\title{
Disparities in Exposure to Air Pollution during Pregnancy
}

\author{
Tracey J. Woodruff, ${ }^{1}$ Jennifer D. Parker, ${ }^{2}$ Amy D. Kyle, ${ }^{3}$ and Kenneth C. Schoendorf
}

${ }^{1}$ National Center for Environmental Economics, U.S. Environmental Protection Agency, San Francisco, California, USA; ${ }^{2}$ Infant and Child Health Studies Branch, National Center for Health Statistics, Centers for Disease Control and Prevention, Hyattsville, Maryland, USA; ${ }^{3}$ School of Public Health, University of California, Berkeley, California, USA

\begin{abstract}
Previous research shows poorer birth outcomes for racial and ethnic minorities and for persons with low socioeconomic status (SES). We evaluated whether mothers in groups at higher risk for poor birth outcomes live in areas of higher air pollution and whether higher exposure to air pollution contributes to poor birth outcomes. An index representing long-term exposure to criteria air pollutants was matched with birth certificate data at the county level for the United States in 1998-1999. We used linear regression to estimate associations between the air pollution index and maternal race and educational attainment, a marker for SES of the mother, controlling for age, parity, marital status, and region of the country. Then we used logistic regression models both to estimate likelihood of living in counties with the highest levels of air pollution for different racial groups and by educational attainment, adjusting for other maternal risk factors, and to estimate the effect of living in counties with higher levels of air pollution on preterm delivery and births small for gestational age (SGA). Hispanic, African-American, and Asian/Pacific Islander mothers experienced higher mean levels of air pollution and were more than twice as likely to live in the most polluted counties compared with white mothers after controlling for maternal risk factors, region, and educational status [Hispanic mothers: adjusted odds ratio $(\mathrm{AOR})=4.66 ; 95 \%$ confidence interval (95\% CI), 1.92-11.32; African-American mothers: AOR = 2.58; 95\% CI, 1.00-6.62; Asian/Pacific Islander mothers: $\mathrm{AOR}=2.82 ; 95 \% \mathrm{CI}, 1.07-7.39]$. Educational attainment was not associated with living in counties with highest levels of the air pollution index (AOR $=0.95$; 95\% CI, $0.40-2.26$ ) after adjusting for maternal risk factors, region of the country, and race/ethnicity. There was a small increase in the odds of preterm delivery (AOR $=1.05 ; 95 \% \mathrm{CI}, 0.99-1.12$ ) but not SGA $(A O R=0.96 ; 95 \% \mathrm{CI}, 0.86-1.07)$ in a county with high air pollution. Additional risk of residing in areas with poor air quality may exacerbate health problems of infants and children already at increased risk for poor health. Key words: air pollution, birth outcomes, criteria air pollutants, environmental justice. Environ Health Perspect 111:942-946 (2003). doi:10.1289/ehp.5317 available via $h t t p: / / d x$.doi.org/ [Online 9 January 2003]
\end{abstract}

Disparities in health status between different socioeconomic and racial and ethnic groups have been a persistent problem in the United States (Council of Economic Advisors for the President's Initiative on Race 1998; Kramer et al. 2000; National Center for Health Statistics 2001; Pamuk et al. 1998). Despite increasing research, the disparities are not fully explained, and the policies to reduce them have been elusive. Infant mortality rates, for example, are considerably higher for infants of mothers with lower educational attainment [educational attainment is a commonly used, although imprecise, measure of socioeconomic status (SES)] (Kramer et al. 2000). Infant mortality rates are also higher for infants born to African-American mothers (Kramer et al. 2000; Pamuk et al. 1998). These perinatal disparities in health status continue through childhood (National Center for Health Statistics 2001). For example, poor children are more likely than nonpoor children to be in fair or poor health and to suffer activity limitations from chronic conditions (Federal Interagency Forum on Child and Family Statistics 2002); childhood asthma is more common among poor compared with nonpoor children [U.S. Environmental Protection Agency (U.S. EPA) 2003].
Environmental pollutants can add another burden to groups already at higher risk of disease and may have disparate impacts on people in higher risk groups (Institute of Medicine 1999). A report from the Institute of Medicine concluded that identifiable communities "experience higher levels of exposure to environmental stressors in terms of both frequency and magnitude" and that "factors directly related to their socioeconomic status ... can make people in these communities more susceptible to the adverse health effects of these environmental hazards" (Institute of Medicine 1999). Although the Institute of Medicine acknowledged limitations in the data available about the distribution of environmental exposures and risks, it described this combination of higher exposures and greater susceptibility as a form of "double jeopardy" (Institute of Medicine 1999).

Studies suggest that certain populations of color, particularly African Americans, are more likely to live in areas with a higher density of particular sources of pollution, such as major industrial sources (Perlin et al. 1999, 2001) and waste-generating facilities (Anderton and Anderson 1994; Perlin et al. 2001). These studies assess whether people of different race/ethnic groups have different exposures, defined as living near particular sources. This approach leaves out other sources of air pollution, such as that from motor vehicles, that could be important. Using air quality monitoring data is a useful way to evaluate the potential disparities in exposure, because it can provide measurements that represent exposures from all sources, although it does not identify the sources that contribute to the air pollution.

To date, there has been little research, using more direct measurements of exposure, such as monitoring data, on how environmental stressors may differentially affect people in different socioeconomic and racial/ethnic groups and exacerbate health problems of those with poorer health status.

Air pollution has been shown to adversely affect health, particularly the health of children. An extensive literature reports adverse health effects resulting from exposure to ambient concentrations of ozone, particulate matter, and, in some studies, sulfur dioxide, nitrogen dioxide, and carbon monoxide (Bates 1995; Dockery et al. 1993; Koenig 1999; Samet et al. 2000a, 2000b; Schwartz et al. 1994). These evaluations of health and air quality usually have focused on individual pollutants. Among children, exposures to ozone and particulate matter are associated with decreases in lung function and increased incidence of cough and wheezing (Dockery et al. 1989, 1996; Raizenne et al. 1996; Schwartz et al. 1994), as well as exacerbation of existing respiratory conditions, including asthma, which can lead to emergency room visits and hospitalization (Lipsett et al. 1997; McConnell et al. 1999; Norris et al. 1999; Schwartz et al. 1993; Studnicka et al. 1997; Tolbert et al. 2000).

Numerous studies in the United States and in other countries have found links between individual components of air pollution and adverse birth outcomes, such as low birth weight, premature birth, and infant mortality (Bobak 2000; Bobak and Leon 1999; Bobak et al. 2001; Dejmek et al. 1999; Ha et al. 2001; Loomis et al. 1999; Maisonet et al. 2001; Ritz and Yu 1999; Ritz et al. 2000; Rogers et al.

Address correspondence to T.J. Woodruff, National Center for Environmental Economics, U.S. EPA, 75 Hawthorne St. (SPE-1), San Francisco, CA 94105 USA. Telephone: (415) 744-1383. Fax: (415) 7442360. E-mail: woodruff.tracey@epa.gov

The views expressed in this report are those of the authors, and they do not necessarily represent those of the U.S. Environmental Protection Agency.

The authors declare they have no conflict of interest. Received 30 October 2001; accepted 9 January 2003. 
2000; Wang et al. 1997; Woodruff et al. 1997). Several of these studies have evaluated the relationship between different components of air pollution and low birth weight (Bobak 2000; Bobak and Leon 1999; Bobak et al. 2001; Dejmek et al. 1999; Ha et al. 2001; Maisonet et al. 2001; Ritz and Yu 1999; Rogers et al. 2000; Wang et al. 1997), with mixed results among the studies.

Studies of the impact of air pollution on birth outcomes and on public health have focused on individual pollutants, although the population is exposed to multiple pollutants. We were interested in whether any group of mothers are more likely than others to suffer a higher burden of air pollution and in the potential impacts of chronic exposure to a mixture of air pollutants on birth outcomes.

In this study, we assessed whether mothers with lower SES, as measured by lower educational attainment, and mothers in various race/ethnic groups were more likely to live in areas with higher aggregate levels of air pollution. We also looked at whether increased exposure to aggregate air pollution contributes to poorer birth outcomes and, if so, whether the exposure explained, in part, known disparities in birth outcomes. The birth outcomes considered were preterm delivery and small size for gestational age (SGA). This objective follows from the known relationships between SES and health and between air quality and health, and addresses the Institute of Medicine findings (1999) suggesting a relationship between social class, race/ethnicity, and environmental pollution.

\section{Methods}

Air pollution exposure estimates. We obtained data on measured concentrations of five "criteria” pollutants (as defined by the U.S. EPA) particulate matter with diameters of $10 \mu \mathrm{m}$ or less $\left(\mathrm{PM}_{10}\right)$, ozone, carbon monoxide, nitrogen dioxide, and sulfur dioxide-from the U.S. EPA's Aerometric Information Reporting System, a database of ambient air quality measurements made by federal, state, and local air pollution control agencies (U.S. EPA 2000). We used data from all air quality monitors, except those specifically designed to collect background concentrations (concentrations that are expected absent anthropogenic sources) or source-specific concentrations, to calculate an annual average value for each county for each pollutant. Monitoring data were available for three or more pollutants in 263 counties in 1998-1999.

Air pollution index. We created an air pollution index representing long-term exposure to the five criteria pollutants for 1998-1999. A brief description of the index, which we have modified slightly here, is given in this article. The index is more fully described elsewhere (Kyle et al. 2002). The county-based index of long-term exposure to air pollution is created by dividing the annual average of the measured values for each pollutant by the National Ambient Air Quality Standard for that pollutant (Kyle et al. 2002). The ratios for each pollutant (the annual concentration divided by the value for the appropriate standard) were scaled to a five-point scale and then averaged together to generate an index value representing the net burden of these five pollutants over 1 year, with each weighted equally. For example, an index value of 5 could represent an area that exactly reached the National Ambient Air Quality Standards for all five pollutants throughout the year for which the index was calculated. National Ambient Air Quality Standards for each criteria pollutant are set at a level to protect public health. We used the following measures for each of the pollutants: a) ozone, annual mean of the maximum 1-hr value per day; $b$ ) particulate matter, sulfur dioxide, and nitrogen dioxide, annual mean of the average daily (24-hr) values; c) carbon monoxide, annual mean of the highest 8-hr period for each day.

U.S. counties differed with respect to which pollutants were monitored in 1998 and 1999. For those counties in which a particular pollutant was not monitored, we generated a default value for use in calculating the index. To create default values, we divided up the country into seven regions, to obtain large geographic areas that were sufficiently distinct in their air pollution sources. These were based on the regions defined by Samet et al. (2000b) in their analyses of morbidity and mortality from air pollution across the United States. The regions are the Northwest, the Southwest, southern California, the upper Midwest, the industrial Midwest, the Northeast, and the Southeast. For each region, we defined the default value for each pollutant as the average of the measured values for that pollutant in the region. For example, for particulate matter, the default value in the Southwest was the average of the monitored values in the Southwest.

For this analysis, we use the air index values for counties that have monitoring data for three or more pollutants.

Natality data. We used the U.S. Natality files for 1998-1999 (National Center for Health Statistics 2003) to obtain information about maternal characteristics (educational attainment, age, parity, marital status, and racial/ethnic group) and infant birth outcomes. The natality data were limited to mothers of singleton births who lived in the 48 contiguous states. The few birth records missing birth weight, gestational age, mother's educational status, or parity were excluded $(<2 \%)$. For this analysis, race and Hispanic origin were combined and mothers were placed into one of the following mutually exclusive groups: Asian/Pacific Islander,
American Indian/Alaska Native, African American, Hispanic, and white. Women of Hispanic origin were assigned the Hispanic category, regardless of race. Women were also divided into four different educational groups: less than 12 years of education, 12 years of education, 13-15 years of education, and 16 years or more of education. Educational attainment was used as a proxy, albeit imperfect, for SES (Federal Interagency Forum on Child and Family Statistics 2002; Kramer et al. 2000).

Two infant birth outcomes were considered: preterm delivery (defined as delivery after fewer than 37 complete weeks of gestation) and birth of an SGA child, defined as birth weight less than the 10th percentile at each week of gestational age. Although low birth weight (birth weight $<2,500 \mathrm{~g}$ ) has been used as a marker of poor birth outcomes in prior studies of air quality, associations between low birth weight and air pollution are more difficult to interpret because birth weight is influenced by both length of gestation and rate of growth.

Linkage. Records for women with eligible births from the Natality file were linked to values for the air pollution index at the county level by county. In this study, we focus our analysis on counties that had monitoring data for three or more pollutants to concentrate on values of the air index that were mostly based on monitoring data. Of the 7,355,696 births recorded in 1998 and 1999, 56\% of the births were to mothers living in an area with monitoring data for three or more monitors and are included in this study $(4,098,740$ births in 264 counties). The study sample overrepresented African-American, Asian, and Hispanic mothers, but the maternal factors and birth outcomes for the births in the counties with three or more monitors were similar to those from all counties (Table 1).

Analytical methods. We assumed a linear form of the index and modeled the relationship between the index and demographic variables using two straightforward approaches.

First, we examined the index as a continuous variable. Adjusted means, derived from a general linear regression model, were used to look at the relationship between air quality and SES (measured by educational attainment) and race/ethnic group. In addition to race/ethnicity and educational status, the regression models also included other known risk factors and potential confounders (maternal age, parity, and marital status), as well as categorical variables describing the nine census divisions of the country (Pickle et al. 1999), excluding Alaska and Hawaii. The regional designations were included to capture potential regional variation in the composition of the index. Robust standard errors were calculated to take into account the clustering within counties using Stata 6.0 (Stata Corporation 1999). 
Second, we focused on areas with the poorest air quality. For this analysis, we divided the women into two groups: those who lived in counties above and those who lived in counties below the county-specific 90th percentile value of the index, calculated from the births in counties linked to three or more monitors. It seemed reasonable to classify the areas of poorest air quality as the top 10th percentile of the index, although this choice is somewhat arbitrary, in that other percentiles around 10 , such as the 5 th or 15 th, could have been chosen. We used a logistic regression model to model the top decile of pollution as a function of educational attainment and race while adjusting for other maternal risk factors that may confound the relationship (age, parity, and marital status). Division of the country was considered in these models but ultimately was not included because the counties with high index values are only contained in four divisions. models were fitted for each birth outcome as a
Finally, additional logistic regression

function of air quality, adjusting for educational attainment, race/ethnicity, age, parity, marital status, and census division.

\section{Results}

The mean level of the air pollution index among the births in our study sample was 2.14 ; $90 \%$ of the values were between 1.16 and 2.72 . About $10 \%$ of the births occur in the counties in the highest decile of the air index.

The unadjusted mean level of the air pollution index was lower for white mothers (mean $=2.08)$ and American Indian/Alaska Native mothers $($ mean $=2.03)$ than for Hispanic $($ mean $=2.23)$, African-American (mean $=2.17)$, and Asian/Pacific Islander $($ mean $=2.16)$ mothers $($ Table 2$)$. Race was significantly associated with the mean air index for Hispanic and African-American mothers compared with white mothers after adjusting for educational attainment, age, parity, marital status, and region of the country (Table 2). The $\beta$-value for Asian/Pacific

Table 1. Percent distribution of maternal factors and infant birth outcomes 1998-1999 for birth outcomes in all counties and in counties that have monitoring data for three or more pollutants.

\begin{tabular}{lcc}
\hline Maternal factors and infant birth outcomes & All counties & \\
\hline Maternal education (years) & & $\begin{array}{c}\text { Counties with monitoring data } \\
\text { for three or more pollutants }\end{array}$ \\
$<12$ & 21.9 & 23.1 \\
12 & 32.4 & 30.5 \\
$13-15$ & 22.1 & 21.6 \\
$\geq 16$ & 23.6 & 24.8 \\
Maternal race/ethnicity & & 0.5 \\
American Indian/Alaska Native & 0.9 & 5.7 \\
Asian/Pacific Islander & 4.1 & 17.9 \\
African American & 15.0 & 25.3 \\
Hispanic & 18.8 & 50.6 \\
White & 61.2 & 11.7 \\
Maternal age (years) & & 74.2 \\
$<20$ & 12.5 & 14.1 \\
$20-34$ & 74.7 & 65.2 \\
$>34$ & 12.8 & 41.1 \\
Percent married & 67.2 & 9.0 \\
Percent first birth & 40.9 & 9.9 \\
Birth outcomes & & \\
SGA & 8.9 & \\
Preterm delivery & 9.8 & \\
\hline
\end{tabular}

${ }^{a} n=7,355,696 .{ }^{b} n=4,098,740$.

Table 2. Mean air index value and regression coefficients for counties that have monitoring data for three or more pollutants.

\begin{tabular}{lcrr}
\hline & & \multicolumn{2}{c}{ Regression coefficients (95\% Cls) } \\
\cline { 4 - 4 } Maternal education and race/ethnicity & Mean air index value & Unadjusted & Adjusted $^{a}$ \\
\hline Maternal education (years) & & & \\
$\quad<12$ & 2.19 & $0.08(0.01-0.15)$ & $0.00(-0.02-0.03)$ \\
12 & 2.14 & $0.01(-0.02-0.03)$ & $-0.02(-0.04-0.00)$ \\
$13-15$ & 2.12 & Reference & Reference \\
$\geq 16$ & 2.11 & & $0.15(0.00-0.29)$ \\
Maternal race/ethnicity & & $0.09(0.05-0.14)$ & $0.12(0.04-0.21)$ \\
Hispanic & 2.23 & $0.08(-0.03-0.19)$ & $0.05(0.00-0.0 .14)$ \\
African American & 2.17 & $-0.06(-0.21-0.10)$ & $-0.07(-0.17-0.04)$ \\
Asian/Pacific Islander & 2.16 & Reference & Reference \\
American Indian/Alaska Native & 2.03 & 2.08 &
\end{tabular}

${ }^{a}$ Adjusted for region, age, parity, and marital status; mean by education also adjusted for race/ethnicity, and mean by race/ethnicity also adjusted for education.
Islander mothers was marginally statistically significant (the 95\% lower confidence bound is 0 ) after adjusting for potential confounders. There was no difference between the American Indian/Alaska Native mothers and the white mothers after adjustment for educational attainment, region of the country, age, parity, and marital status.

Looking at just the unadjusted mean values of the index, mothers with lower educational attainment lived in areas with a higher mean level of the air pollution index than did mothers with higher educational attainment (Table 2). However, results from the regression analysis found no association between education levels and the air index after adjusting for race/ethnicity, age, parity, marital status, and region of the country (Table 2 ).

Hispanic mothers were the most likely to live in areas with the highest decile of the air index compared with white mothers (Table 3), consistent with the findings for the mean level of the index. Similarly, these disparities persisted after controlling for educational attainment, region of the country, age, parity, and marital status. The adjusted odds ratio (AOR) comparing Hispanic with white mothers living in an area with the highest decile of the air pollution index was 4.66 (95\% CI, 1.92-11.32). For African-American mothers, the AOR was 2.58 (95\% CI, 1.00-6.62), and for Asian/Pacific Islander mothers the AOR was 2.82 (95\% CI, 1.07-7.39) (Table 3).

Mothers with lower educational attainment were not more likely to live in counties with especially poor air quality (Table 3 ). As found for the mean level of the index, the relationship between educational attainment and air pollution was diminished after controlling for maternal race and region. The adjusted odds of living in the highest decile of poor air quality was 0.95 (95\% CI, 0.40-2.26) for women with fewer than 12 years of education compared with women with 16 or more years of education.

We also evaluated the relationship between the race/ethnicity and education and the air pollution index for all counties, regardless of the number of monitored pollutants in each county. We found similar results for all counties as for counties with monitoring data for three or more pollutants by race/ethnicity, with a significant association between increased levels of air pollution and Hispanic, Asian/Pacific Islander, and African-American race/ethnicity (data not shown). American Indian/Alaska Native was significantly not associated with living in an area of higher air pollution compared with whites. Similar to the results by race/ethnicity for all counties, we found no relationship between education and air quality when looking at all counties (data not shown).

Increasing levels of air pollution were associated with preterm delivery but were not associated with SGA (Table 4). After adjustment 
for maternal race, educational status, other maternal risk factors, and region of the country, the odds of a preterm delivery for mothers living in counties with the highest decile of air pollution remained elevated compared with those living in the remaining counties but was reduced (AOR $=1.05$; 95\% CI, 0.99-1.12). Similar results were seen for the continuous model and preterm delivery $(\mathrm{AOR}=1.04 ; 95 \%$ CI, $1.00-1.08$ per unit increase in the air pollution index; the interquartile range is about half a unit of the index, so the resulting AOR would be about half). There was no relationship between SGA and the air pollution index after adjusting for maternal race, educational status, other maternal risk factors, and region of the country (for continuous model, AOR = 0.99; 95\% CI, 0.93-1.06).

The inclusion of the air pollution index in the regression models did not attenuate wellestablished relationships between maternal race and birth outcomes. For example, the AORs for SGA births for African-American mothers compared with white mothers were 2.0, regardless of the level of the air pollution index. Similarly, the ORs for preterm births for African-American mothers compared with white mothers were 1.9, regardless of the level of the air pollution index. Consequently, we cannot conclude that differential air pollution exposure levels explain known disparities in birth outcomes.

\section{Discussion}

We found that Hispanic, African-American, and Asian/Pacific Islander mothers were more likely to live in areas with higher levels of air pollution than were white mothers. This result appears to be independent of the other risk factors (age, parity, educational attainment, and marital status) considered in this analysis. Adjusting for these factors did not substantially change the observed relationship between maternal race and air pollution. Decreasing levels of the mother's educational attainment were not associated with increasing levels of air pollution, after adjusting for race/ethnicity, age, parity, and marital status. This suggests that at least for this measure of air pollution, the relationship between race/ethnicity and residence in areas with more air pollution is stronger than the relationship between low SES and living in areas with more air pollution.

Most studies evaluating the burden of pollution among different racial and ethnic groups have focused on living near different types of emissions or industrial facilities. Fewer have been published using more specific measures of exposure such as the index reflecting ambient concentrations of air pollutants used in this analysis. Moreover, in this analysis we considered chronic exposure to several pollutants. Using an index of air pollution represents the net air pollution mixtures experienced by the public. By relating the measured concentrations to National Air Quality Standards, the index attempts to account for the differing severity of the individual pollutants. Unfortunately, monitoring is not conducted in all counties for all the pollutants of interest, necessitating the use of default values in a number of areas. Furthermore, for two of the pollutants (ozone and carbon monoxide) the individual pollutant measure is based on a short-term standard, which does not necessarily reflect the chronic effects of exposure over the year. Finally, it is unknown how long the mothers included in this study lived in the county recorded for residence on the birth certificate, further limiting our exposure measurements.

We found a moderate association between exposure to air pollution and preterm delivery but did not find an association between SGA infants and air pollution. Recent research has suggested that air pollution is associated with poor birth outcomes, at least for some mothers (Ha et al. 2001; Maisonet et al. 2001; Ritz and Yu 1999; Ritz et al. 2000; Rogers et al. 2000). The results in these other analyses have produced some mixed results. It is possible that confounding by race may be playing a role because African-American mothers are more likely to live in areas of poor air quality and are more likely to have poor birth outcomes. Alternatively, perhaps the results are observed only at higher concentrations. On the other hand, the index used in this analysis may be masking a true relationship between one or more of the individual pollutants, such

Table 3. Odds of exposure to the highest decile of poor air by maternal education and race/ethnicity for counties that have monitoring data for three or more pollutants.

\begin{tabular}{lcc}
\hline \multirow{2}{*}{ Maternal education and race/ethnicity } & \multicolumn{2}{c}{ ORs (95\% Cls) } \\
\cline { 2 - 3 } Maternal education (years) & Unadjusted & Adjusted $^{a}$ \\
$<12$ & $2.13(1.42-3.18)$ & $0.95(0.40-2.26)$ \\
12 & $1.22(0.92-1.61)$ & $0.93(0.74-1.18)$ \\
$13-15$ & $1.10(0.85-1.42)$ & $0.96(0.73-1.26)$ \\
$\geq 16$ & Reference & Reference \\
Maternal race/ethnicity & & \\
Hispanic & $4.76(2.06-11.03)$ & $4.66(1.92-11.32)$ \\
African American & $2.59(0.92-7.26)$ & $2.58(1.00-6.62)$ \\
Asian/Pacific Islander & $2.84(1.06-7.60)$ & $2.82(1.07-7.39)$ \\
American Indian/Alaska Native & $0.97(0.44-2.09)$ & $0.95(0.40-2.26)$ \\
White & Reference & Reference \\
\hline
\end{tabular}

${ }^{a}$ Adjusted for age, parity, and marital status; OR by education also adjusted for race/ethnicity, and OR by race/ethnicity also adjusted for education.

Table 4. Unadjusted and adjusted ORs for preterm delivery and SGA births by air pollution index for counties that have monitoring data for three or more pollutants.

\begin{tabular}{llc}
\hline & \multicolumn{2}{c}{ ORs (95\% Cls) } \\
\cline { 2 - 3 } Infant outcome and risk measures & \multicolumn{1}{c}{ Unadjusted } & Adjusted $^{a}$ \\
\hline Preterm delivery & $1.11(1.00-1.25)$ & $1.04(1.00-1.08)$ \\
$\quad$ Continuous index, per unit increase & $0.99(0.90-1.08)$ & $1.05(0.99-1.12)$ \\
Highest decile of index & & \\
SGA & $1.10(0.97-1.26)$ & $0.99(0.93-1.06)$ \\
Continuous index, per unit increase & $0.92(0.86-0.99)$ & $0.96(0.86-1.07)$ \\
Highest decile of index &
\end{tabular}

aLogistic regression models included maternal education, maternal race/ethnicity, parity, age, marital status, and region of the country. 


\section{REFERENCES}

Anderton D, Anderson A. 1994. Environmental equity: the demographics of dumping. Demography 31:229-248.

Avol EL, Gauderman WJ, Tan SM, London SJ, Peters JM. 2001. Respiratory effects of relocating to areas of differing air pollution levels. Am J Respir Crit Care Med 164(11):2067-2072.

Bates DV. 1995. The effects of air pollution on children. Environ Health Perspect 103(suppl 6):49-53.

Bobak M. 2000. Outdoor air pollution, low birth weight, and prematurity. Environ Health Perspect 108(2):173-176.

Bobak M, Leon DA. 1999. Pregnancy outcomes and outdoor air pollution: an ecological study in districts of the Czech Republic 1986-8. Occup Environ Med 56(8):539-543.

Bobak M, Richards M, Wadsworth M. 2001. Air pollution and birth weight in Britain in 1946. Epidemiology 12(3):358-359.

Council of Economic Advisors for the President's Initiative on Race. 1998. Changing America. Indicators of Social and Economic Well-Being by Race and Hispanic Origin. Washington, DC:Council of Economic Advisors for the President's Initiative on Race.

Dejmek J, Selevan SG, Benes I, Solansky I, Sram RJ. 1999. Fetal growth and maternal exposure to particulate matter during pregnancy. Environ Health Perspect 107:475-480.

Dockery DW, Cunningham J, Damokosh Al, Neas LM, Spengler JD, Koutrakis $P$, et al. 1996. Health effects of acid aerosols on North American children: respiratory symptoms. Environ Health Perspect 104:500-505

Dockery DW, Pope CA III, Xu X, Spengler JD, Ware JH, Fay ME et al. 1993. An association between air pollution and mortality in six U.S. cities. N Engl J Med 329(24):1753-1759.

Dockery DW, Speizer FE, Stram DO, Ware JH, Spengler JD, Ferris BG Jr. 1989. Effects of inhalable particles on respiratory health of children. Am Rev Respir Dis 139(3):587-594.

Federal Interagency Forum on Child and Family Statistics. 2002. America's Children: Key National Indicators of Well-Being, 2001. Washington, DC:Federal Interagency Forum on Child and Family Statistics.

Ha EH, Hong YC, Lee BE, Woo BH, Schwartz J, Christiani DC. 2001. Is air pollution a risk factor for low birth weight in Seoul? Epidemiology 12(6):643-648.

Institute of Medicine. 1999. Toward Environmental Justice: Research, Education and Health Policy Needs. Washington, DC:National Academy Press.

Koenig J0. 1999. Air pollution and asthma. J Allergy Clin Immunol 104(4 pt 1):717-722

Kramer MS, Seguin L, Lydon J, Goulet L. 2000. Socio-economic disparities in pregnancy outcome: why do the poor fare so poorly? Paediatr Perinat Epidemiol 14(3):194-210.

Kyle AD, Woodruff TJ, Buffler PA, Davis DL. 2002. Use of an index to reflect the aggregate burden of long-term exposure to criteria air pollutants in the United States. Environ Health Perspect 110(suppl 1):95-102.

Lipsett M, Hurley S, Ostro B. 1997. Air pollution and emergency room visits for asthma in Santa Clara County, California. Environ Health Perspect 105:216-222.

Loomis D, Castillejos M, Gold DR, McDonnell W, Borja-Aburto VH. 1999. Air pollution and infant mortality in Mexico City. Epidemiology 10(2):118-123.

Maisonet M, Bush T, Correa A, Jaakkola J. 2001. Relation between ambient air pollution and low birth weight in the northeastern United States. Environ Health Perspect 109(suppl 3):351-356.

McConnell R, Berhane K, Gilliland F, London SJ, Islam T, Gauderman WJ, et al. 2002. Asthma in exercising children exposed to ozone: a cohort study. Lancet 359(9304):386-391.

McConnell R, Berhane K, Gilliland F, London SJ, Vora H, Avol E, et al. 1999. Air pollution and bronchitic symptoms in southern California children with asthma. Environ Health Perspect 107:757-760.

National Center for Health Statistics. 2003. Natality Data, Public Use Data Files. Hyattsville, MD:National Center for Health Statistics. Available: http://www.cdc.gov/nchs/products/ elec_prods/subject/natality.htm [accessed 23 April 2003]. 2001. Health, United States, 2001 with Urban and Rura Health Chartbook. Hyattsville, MD:National Center for Health Statistics.

Norris G, YoungPong SN, Koenig JQ, Larson TV, Sheppard L, Stout JW. 1999. An association between fine particles and asthma emergency department visits for children in Seattle. Environ Health Perspect 107:489-493.

Pamuk E, Makuc D, Heck K, Reuben C, Lochner K. 1998. Socioeconomic Status and Health Chartbook. Health United States, 1998. Hyattsville, MD:National Center for Health Statistics.

Perlin SA, Sexton K, Wong DW. 1999. An examination of race and poverty for populations living near industrial sources of air pollution. J Expo Anal Environ Epidemiol 9(1):29-48.

Perlin SA, Wong D, Sexton K. 2001. Residential proximity to industrial sources of air pollution: interrelationships among race, poverty, and age. J Air Waste Manag Assoc 51(3):406-421.

Pickle L, Mungiole M, Jones G, White A. 1999. Exploring spatia patterns of mortality: the new atlas of United States mortality. Stat Med 18:3221-3220.

Raizenne M, Neas LM, Damokosh Al, Dockery DW, Spengler JD, Koutrakis P, et al. 1996. Health effects of acid aerosols on North American children: pulmonary function. Environ Health Perspect 104:506-514.

Ritz B, Yu F. 1999. The effect of ambient carbon monoxide on low birth weight among children born in southern California between 1989 and 1993. Environ Health Perspect 107:17-25.

Ritz B, Yu F, Chapa G, Fruin S. 2000. Effect of air pollution on preterm birth among children born in southern California between 1989 and 1993. Epidemiology 11(5):502-511.

Rogers JF, Thompson SJ, Addy CL, McKeown RE, Cowen DJ, Decoufle P. 2000. Association of very low birth weight with exposures to environmental sulfur dioxide and total suspended particulates. Am J Epidemiol 151(6):602-613.

Samet JM, Dominici F, Curriero FC, Coursac I, Zeger SL. 2000a. Fine particulate air pollution and mortality in 20 U.S. cities, 1987-1994. N Engl J Med 343(24):1742-1749.

Samet JM, Zeger SL, Dominici F, Curriero FC, Coursac I, Dockery D, et al. 2000b. The National Morbidity, Mortality, and Air Pollution Study. Part II: Morbidity and Mortality from Air Pollution in the United States. Boston, MA:Health Effects Institute.

Schwartz J, Dockery DW, Neas LM, Wypij D, Ware JH, Spengler JD, et al. 1994. Acute effects of summer air pollution on respiratory symptom reporting in children. Am J Respir Crit Care Med 150(5 pt 1):1234-1242.

Schwartz J, Slater D, Timothy V, Pierson W, Koenig J. 1993. Particulate air pollution and hospital emergency room visits for asthma in Seattle. Am J Respir Crit Care Med 147:826-831.

Stata Corporation. 1999. Stata Statistical Software. College Station, TX:Stata Corporation.

Studnicka M, Hackl E, Pischinger J, Fangmeyer C, Haschke N, Kuhr J, et al. 1997. Traffic-related $\mathrm{NO}_{2}$ and the prevalence of asthma and respiratory symptoms in seven year olds. Eur Respir J 10(10):2275-2278.

Tolbert PE, Mulholland JA, Maclntosh DL, Xu F, Daniels D, Devine $0 \mathrm{~J}$, et al. 2000. Air quality and pediatric emergency room visits for asthma in Atlanta, Georgia, USA. Am J Epidemiol 151(8):798-810.

U.S. EPA. 2000. Aerometric Information Retrieval System. Research Triangle Park, NC:U.S. Environmental Protection Agency.

. 2003. America's Children and the Environment: Measures of Contaminants, Body Burdens, and Illnesses. Washington, DC:U.S. Environmental Protection Agency.

Wang X, Ding H, Ryan L, Xu X. 1997. Association between ai pollution and low birth weight: a community-based study. Environ Health Perspect 105:514-520.

Woodruff TJ, Grillo J, Schoendorf KC. 1997. The relationship between selected causes of postneonatal infant mortality and particulate air pollution in the United States. Environ Health Perspect 105:608-612. 